\title{
Lei de Acesso à Informação: Direito Comparado entre Brasil e Estados Unidos.
}

\section{Law on Access to Information: Compared Law between Brazil and the United States.}

\section{Resumo}

Este artigo tem por escopo descrever e analisar a Lei de Acesso à Informação (Lei $\mathrm{n}^{\circ}$ 12.527/2011) no Brasilcomparando-a com o modelo norte-americano. Buscou-se contextualizar o direito à informação no âmbito internacional, relacionando sua previsão nos Tratados e Convenções de maior repercussão. Depois, são abordados os aspectos históricos que ilustram a evolução desse direito fundamental no Brasil. O mesmo roteiro foi utilizado para descrever os Estados Unidos da América (EUA). A pesquisa levanta a hipótese de que os EUA não possui legislação mais avançada que o Brasil. O problema encontrado foi identificar de que forma o acesso à informação é protegido em países com direito amparado nos costumes, como é o caso dos EUA. O estudo foi feito com base nos nove princípios que caracterizam um regime de direito à informação, segundo o relatório da UNESCO "Liberdade de Informação: um estudo de direito comparado", assinado por Toby Mendel.

Palavras-chave: Direitos Humanos. Direito Constitucional Comparado. Liberdade de Informação. Lei de Acesso à Informação.

\section{Abstract}

This article aims to describe and analyze the Law on Access to Information (Law 12.527/2011) in Brazil, comparing it with the North American model. The aim was to contextualize the right to information in the international context, relating its prediction in the Treaties and Conventions of greater repercussion. Then, the historical aspects that illustrate the evolution of this fundamental right in Brazil are discussed. The same script was used to describe the United States of America. The research raises the hypothesis that the US has no more advanced legislation than Brazil. The problem was to identify how access to information is protected in countries with customary rights, such as the US. The study was based on the nine principles that characterize a right to information regime, according to the UNESCO report "Freedom of Information: A Comparative Law Study", signed by Toby Mendel.

Keywords: Human Rights. Comparative Constitutional Law. Freedom of Information. Law of Access to Information.

\footnotetext{
${ }^{1}$ Jornalista (UFMT), mestre em Direito (UNICEUB-DF), especialista em Gestão da Comunicação (UNICEUB-DF) e pesquisador do tema Fake News.
} 


\section{1 - Introdução}

O enfrentamento das demandas por Justiça, o combate à corrupção e a transparência nas instituições públicas dependem da compreensão de um direito cada vez mais debatido e acessado nas nações democráticas: o direito à informação.

Previsto nos principais textos referentes a direitos humanos fundamentais, o direito de acesso à informação é fundamental para a formação da opinião pública. Ele é imprescindível para a concretização de todos os demais direitos humanos, já que a informação leva o indivíduo a conhecer os seus próprios direitos.As políticas de transparência, por conseguinte,ao mesmo tempo que obrigam quem opera as políticas públicas a justificar suas decisões;aproximamo cidadão da tomada de decisões, da definição de prioridades, formulação de planos de execução e alocação de recursos.

Se levarmos em conta a visão econômica do direito, que relaciona a questão das políticas públicas com o nível de desenvolvimento de uma sociedade, pode-se dizer que o direito à informação no Brasil passa a ser reconhecido com mais vigor na medida em que o país se desenvolve economicamente. A avaliação também ajuda a justificar o porquê de países como os Estados Unidos da América serem mais avançadas em termos de participação política do cidadão, controle social e até na equidade da representatividade legislativa.

É nesse cenário que o presente artigo pretende descrever e analisar a Lei de Acesso à Informação (Lei $\mathrm{n}^{\circ}$ 12.527/2011) no Brasil enquanto política pública de transparência e fomento à participação popular, comparando-a ao modelo norte-americano.

Apesar de o federalismo americano divergir do brasileiro de tal forma que interfere diretamente no alcance, aplicação e conteúdo de suas normas, leva-se em conta que o fortalecimento dos canais de accountability e participação popular são problemas comuns às principais democracias do mundo. Sendo assim, buscou-se comparar se as soluções aplicadas pelos dois países estão em consonância com a proteção do direito à informação.

A hipótese levantada é a de que, embora seja considerado referência em transparência pública, os EUA não dispõe de legislação mais avançada que o Brasil. Levanta-se ainda a hipótese de que países com forte tradição democrática e direito amparado nos costumes não estabelecem tudo em lei, nem mudam leis frequentemente. Por essa breve descrição já é possível traçar características marcantes dos países abordados neste artigo.

A tentativa de aplicar os ensinamentos do direito comparado à realidade de dois países distintos segue aqui o entendimento do jurista Rui Pinto Duarte de que a comparação dos Direitos ajuda no conhecimento do próprio Direito. Ou seja, "sendo uma atividade de 
comparação, o Direito Comparado é mais do que o estudo dos vários Direitos; implica a justaposição dos resultados desse estudo e o registo das semelhanças e das diferenças". 2

Ao esbarrar com essa situação, constata-se a necessidade de análise não só do texto legal do Brasil e EUA, mas também de aspectos históricos, econômicos e sociais que superam o tecnicismo, porém, influenciam na consciência jurídica dos países. Foi aí que se definiu como estratégia de comparação o Método Funcional, definido por Marc Ancel como uma das alternativas para descobrir as soluções dadas a um problema atual, individualizado de maneira específica para tal fim. O método trata da função que a categoria, regra ou os objetos de comparação desempenham dentro do respectivo ordenamento:

"Em vez de tomar como ponto de partida abstratamente a regra, a instituição ou mesmo sistema, pode-se partir, de maneira mais completa, de uma situação de fato determinada. Fixaremos, então, de maneira precisa o caso humano ou social que se coloca, buscaremos a solução em um certo número de países, especialmente escolhidos, estando atentos sobretudo aos procedimentos através dos quais cada um desses países chega àquela solução".

Para conseguir comparar o direito de dois países tão distintos, inicialmente, será feita uma abordagem histórica da informação enquanto direito universal e sua consolidação como importante instrumento de fortalecimento democrático. Em seguida, será feita a descrição dos principais pontos da Lei $\mathrm{n}^{\circ} 12.527 / 2011$.

A mesma descrição será feita com a lei que assegura o direito à informação nos Estados Unidos para, então, propormos um quadro comparativo das duas realidades. A metodologia consistiu de pesquisa e revisão bibliográfica no que diz respeito às leis de acesso à informação.

O tema proposto possui importância porque a observação e descrição de duas realidades pode revelar gargalos e apontar soluções de aprimoramento, além de promover o alargamento das fronteiras do conhecimento jurídico. O ponto de partida da análise comparativa é o relatório da UNESCO "Liberdade de Informação: um estudo de direito comparado", assinado por Toby Mendel.

\section{2 - Direito à Informação no mundo}

O mapeamento de todos os instrumentos internacionais de reconhecimento do direito à

${ }^{2}$ DUARTE, Rui Pinto. Uma introdução ao Direito Comparado. Lisboa: Edições Almedina, 2006. Separata da Revista "O Direito IV", 138.ed.

${ }^{3}$ ANCEL, Marc. Utilidade e métodos do Direito Comparado:elementos de introdução geral ao estudo comparativo dos direitos. Porto Alegre, Sérgio Antônio Fabris, 1980. p.117. 
informação está além do escopo deste artigo. Aqui, esboçaremos os principais marcos do sistema internacional que influenciaram e continuam a influenciar o nosso ordenamento.

Já em 1789, a Declaração dos Direitos do Homem e do Cidadão, resultante da Revolução Francesa, em seu artigo 11 defendia a livre comunicação do pensamento e das opiniões - um exemplo histórico da vinculação da informação com a democracia ${ }^{4}$.

A Declaração Universal dos Direitos Humanos, adotada pela Organização das Nações Unidas em 10 de dezembro de 1948, em seu artigo 19, prevê que todo ser humano tem direito à liberdade de opinião e expressão, "este direito inclui a liberdade de, sem interferência, ter opiniões e de procurar, receber e transmitir informações e ideias por quaisquer meios $e$ independentemente de fronteiras $", 5$.

O Pacto Internacional dos Direitos Civis e Políticos (artigo 19), promulgado em 6 de julho de 1992, é outro importante instrumento internacional de proteção ao direito de acesso à informação. Em 1994, aAssociação Interamericana de Imprensa/Conferência Hemisférica sobre Liberdade de Expressão estabeleceu que toda pessoa temo direito de buscar e receber informações, expressaropiniões e divulgá-las livremente. As autoridades precisam serobrigadas por lei a disponibilizar de forma oportuna erazoável as informações geradas pelo setor público.

O conceito é reforçado pela Declaração Interamericana de Princípios de Liberdade de Expressão. Aprovado pela Comissão Interamericana de Direitos Humanos em seu $108^{\circ}$ período ordinário de sessões, celebrado de 16 a 27 de outubro de 2000, o texto diz: "O acesso à informação mantida pelo Estado constitui um direito fundamental de todo indivíduo. Os Estados têm obrigações de garantir pleno exercício desse direito" . $^{\circ}$

O compromisso também foi assumido na Convenção das Nações Unidas contra a Corrupção. A Convenção dotada pela Assembléia-Geral das Nações Unidas entrou em vigor internacional em 14 de dezembro de 2005 . $\mathrm{O}$ artigo $10^{\circ}$ prevê:

"Tendo em conta a necessidade de combater a corrupção, cada Estado Parte, em conformidade com os princípios fundamentais de sua legislação interna, adotará medidas que sejam necessárias para aumentar a transparência em sua administração pública, inclusive no relativo a sua organização, funcionamento e processos de adoção de decisões, quando proceder. Essas medidas poderão incluir, entre outras coisas:

${ }^{4}$ DECLARAÇÃO dos Direitos do Homem e do Cidadão. 1789. Disponível em: http://pfdc.pgr.mpf.mp.br/atuacao-e-conteudos-de-apoio/legislacao/direitoshumanos/declar dir homem cidadao.pdf. Acesso em: 02 ago. 2017.

${ }^{5}$ ONU. Declaração Universal dos Direitos Humanos. 1948. Disponível em: http://www.ohchr.org/EN/UDHR/Documents/UDHR_Translations/por.pdf. Acesso em: 02 ago.2017.

${ }^{6}$ ONU. Declaração Interamericana de Princípios de Liberdade de Expressão. 2000. Acesso em: https://www.cidh.oas.org/basicos/portugues/s.Convencao.Libertade.de.Expressao.htm. Acesso em: 02dez. 2016. 
a) A instauração de procedimentos ou regulamentações que permitam ao público em geral obter, quando proceder, informação sobre a organização, o funcionamento e os processos de adoção de decisões de sua administração pública, com o devido respeito à proteção da intimidade e dos documentos pessoais, sobre as decisões e atos jurídicos que incumbam ao público;

b) A simplificação dos procedimentos administrativos, quando proceder, a fim de facilitar o acesso do público às autoridades encarregadas da adoção de decisões; e

c) A publicação de informação, o que poderá incluir informes periódicos sobre os riscos de corrupção na administração pública."

$\mathrm{O}$ artigo $13^{\circ}$ da mesma Convenção busca promover no âmbito dos Estados a adoção de medidas de fomento à participação cidadã nos assuntos da administração pública, na luta contra e prevenção contra a corrupção. Para tanto, sugere esforço nas nações para:
“a) Aumentar a transparência e promover a contribuição da cidadania aos processos de adoção de decisões;
b) Garantir o acesso eficaz do público à informação;
c) Realizar atividade de informação pública para fomentar a intransigência à corrupção, assim como programas de educação pública, incluídos programas escolares e universitários;
d) Respeitar, promover e proteger a liberdade de buscar, receber, publicar e difundir informação relativa à corrupção. Essa liberdade poderá estar sujeita a certas restrições, que deverão estar expressamente qualificadas pela lei e ser necessárias para: i) Garantir o respeito dos direitos ou da reputação de terceiros; ii) Salvaguardar a segurança nacional, a ordem pública, ou a saúde ou a moral públicas."

Iniciativa internacional que marcou o ano de 2011, a Parceria para Governo Aberto ou OGP (do inglês Open Government Partnership) foi criada para difundir e incentivar globalmente práticas governamentais relacionadas à transparência dos governos, ao acesso à informação pública e à participação social. Além do Brasil, fazem parte da iniciativa EUA, África do Sul, Filipinas, Indonésia, México, Noruega e Reino Unido. Ao todo, 75 países integram a Parceria. Entre outros compromissos relacionados aos direitos humanos e a boa governança, destaca-se o de aumentar o acesso a novas tecnologias para funcionários públicos e cidadãos:

\footnotetext{
"As novas tecnologias oferecem oportunidades para o compartilhamento de informação, e fomentar a participação pública e a colaboração. Temos o objetivo de aproveitar essas tecnologias para tornar mais informações públicas de forma a permitir as pessoas entender o funcionamento de seus governos $\mathrm{e}$ influenciar suas decisões. Comprometemo-nos a desenvolver espaços virtuais acessíveis e seguros como plataformas de fornecimento de serviços, para promover o engajamento do público, e compartilhar informações e ideias. Reconhecemos que a capacidade de acesso equitativa e a baixo custo à tecnologia é um desafio, e comprometemo-nos a buscar maior
}

${ }^{7}$ ONU. Convenção das Nações Unidas contra a Corrupção. 2005.Disponível em: https://www.unodc.org/documents/lpobrazil//Topics corruption/Publicacoes/2007 UNCAC Port.pdf. Acesso em:22 dez. 2016.

${ }^{8}$ ONU. Convenção das Nações Unidas contra a Corrupção. 2005.Disponível em: https://www.unodc.org/documents/lpobrazil//Topics_corruption/Publicacoes/2007_UNCAC_Port.pdf. Acesso em: 22 dez. 2016. 
conectividade em tempo real e móvel, além de identificar e promover o uso de mecanismos alternativos de engajamento cívico. Comprometemo-nos a envolver a sociedade civil e a comunidade empresarial para identificar práticas eficazes e abordagens inovadoras para alavancar novas tecnologias capazes de capacitar as pessoas e promover a transparência no governo. Reconhecemos também que o aumento do acesso à tecnologia exige fomentar a capacidade dos governos e dos cidadãos para usála. Nós nos comprometemos a apoiar e promover o uso de inovações tecnológicas por funcionários públicos e cidadãos. Entendemos, também, que a tecnologia é um complemento, e não um substituto, de informações claras, utilizáveis e úteis".

Mas, qual a reflexão que o plano internacional nos trouxe? Uma análise das legislações de treze países (Azerbaijão, Bulgária, Índia, Jamaica, Japão, Quirguistão, México, Peru, África do Sul, Suécia, Uganda, Reino e Estados Unidos), apontou que:

\begin{abstract}
"Os princípios encontrados em diferentes leis - muitos dos quais de ocorrência frequente - incluem os seguintes: promoção da transparência, prestação de contas e eficiência no governo; controle da corrupção; fomento à participação pública; aumento da capacidade da população de esquadrinhar o exercício do poder público; promoção de uma cultura favorável à democracia e aos direitos humanos e ao estado de direito; aperfeiçoamento da gestão de registros públicos; e o desenvolvimento do esclarecimento público e da cidadania bem informada."10
\end{abstract}

Os levantamentos das experiências internacionais mostram que, antes do Brasil, cerca de 90 países já haviam regulamentado o direito de acesso à informação sob o controle de órgãos públicos, também chamado de direito ao saber, ao conhecimento ou à verdade. Presente na Suécia há mais de 200 anos, nos últimos 10 anos, este reconhecimento se generalizou por todas as regiões do mundo, sendo tema central de discussão nas principais democracias.

\title{
3 - Evolução do Direito à Informação no Brasil
}

Pode-se dizer que somente após o processo de redemocratização, iniciado em 1984 com o movimento pelas eleições diretas e após 21 anos de Ditadura Militar, que o Brasil começou a avançar de fato em termos de modernização legislativa, incluindo o direito a informação no campo das políticas públicas essenciais à modernização do Estado.

Em 1987, no governo de José Sarney, foi desenvolvido o Sistema Integrado de Administração Financeira (SIAFI) do Governo Federal. O sistema, anterior à Constituição de 1988, até hoje é considerado um instrumento moderno e eficaz no controle e acompanhamento dos gastos públicos.

\footnotetext{
${ }^{9}$ Declaração Parceria Governo Aberto. Disponível em: http://www.governoaberto.cgu.gov.br/centralde-conteudo/documentos/arquivos/declaracao-governo-aberto.pdf. Acesso em:4 set. 2017.

${ }^{10}$ MENDEL, Toby. Liberdade de Informação: um estudo de direito comparado. 2. ed. Brasília: Unesco, 2009. p.148.
} 
No governo de Fernando Henrique Cardoso (FHC) foi aprovada a Lei Complementar 101/2000, a Lei de Responsabilidade Fiscal (LRF). Um dos objetivos da LRF foi a implantação do conceito de Responsabilidade Social, que prevê a participação popular na discussão e elaboração dos planos e orçamentos ${ }^{11}$.Foi também no governo FHC que foi criada a Controladoria-Geral da União (CGU).

Já no governo Lula, iniciado em $1^{\circ}$ de janeiro de 2003, foram ampliadas as atribuições da CGU - transformada em 2016 no Ministério da Transparência, Fiscalização e Controladoria-Geral da União. Na segunda metade de seu mandato tem-se outro importante marco na efetivação do direito à informação: a Lei Complementar 131, de 27 de maio de 2009.

Chamada de Lei da Transparência, a LC 131/2009 alterou a redação da Lei de Responsabilidade Fiscal no que se refere à transparência da gestão fiscal, inovando ao determinar a disponibilização, em tempo real pela internet, de informações pormenorizadas sobre a execução orçamentária e financeira da União, dos Estados, do Distrito Federal e dos Municípios.

Quanto à despesa, a lei prevê publicação de todos os atos praticados pelas unidades gestoras no decorrer da execução da despesa, no momento de sua realização, com a disponibilização mínima dos dados referentes ao número do correspondente processo, ao bem fornecido ou ao serviço prestado, à pessoa física ou jurídica beneficiária do pagamento e, quando for o caso, ao procedimento licitatório realizado.

Além do aspecto legal, a Lei da Transparência inaugurou a fase de implantação do Portal Transparência nos estados e municípios brasileiros. O tema governo digital, até então, era tratado apenas na esfera da União. As unidades federativas se viram obrigadas a sistematizar suas informações para torná-las públicas uma vez que a LC 131 definiu ainda prazos de implantação do Portal Transparência, a contar da data de sua publicação (27/05/2009): um ano para a União, os Estados, o Distrito Federal e os Municípios com mais de 100 mil habitantes (maio de 2010); dois anos para os Municípios que tenham entre 50 mil e 100 cem mil habitantes (maio de 2011); e quatro anos para os municípios que tenham até 50 mil habitantes (maio de 2013) ${ }^{12}$.

Também em 2009, o Supremo Tribunal Federal (STF) já antecipava um avanço no que diz respeito ao direito à informação, ao declarar que a Lei de Imprensa (Lei no 5250/67) era incompatível com a Constituição Federal de 1988. No julgamento da Arguição de

\footnotetext{
${ }^{11}$ BRASIL. Lei Complementar $\mathbf{n}^{\circ}$ 101, de 04 de maio de 2000. Estabelece normas de finanças públicas voltadas para a responsabilidade na gestão fiscal e dá outras providências. Disponível em: http://www.planalto.gov.br/ccivil_03/leis/LCP/Lcp101.htm. Acesso em:06 ago. 2017.

${ }^{12}$ BRASIL. Lei Complementar $n^{\circ}$ 131, de 27 de maio de 2009. Acrescenta dispositivos à Lei Complementar n⿳ 101 , de 4 de maio de 2000, que estabelece normas de finanças públicas voltadas para a responsabilidade na gestão fiscal e dá outras providências, a fim de determinar a disponibilização, em tempo real, de informações pormenorizadas sobre a execução orçamentária e financeira da União, dos Estados, do Distrito Federal e dos Municípios. Disponível em: http://www.planalto.gov.br/ccivil 03/leis/lcp/lcp131.htm. Acesso em: 06 ago. 2017.
} 
Descumprimento de Preceito Fundamental (ADPF) 130, o ministro Carlos Ayres Britto (relator) afirmou que além do direito à informação, o cidadão deve exigir dos órgãos públicos a atualização das informações em tempo real, o mesmo fundamento que a Lei da Transparência nos trouxe nessa época.

Em seu voto o ministro avalia ainda que "a publicidade que se eleva à dimensão de verdadeira transparência é o mais aplainado caminho para a fiel aplicação da lei e dos outros três princípios da moralidade, da eficiência e da impessoalidade na Administração Pública”. Sustenta também que os "direitos serão tanto melhor exercidos quanto mais denso e atualizado for o acervo de informações que se possa obter "13.

\section{1 - Lei no 12.527, de 18 de novembro de 2011}

Se considerarmos direitos fundamentais explícitos na Constituição Federal como aqueles expressos formalmente, podemos dizer que o acesso à informação foi consagrado no texto de 1988 como direito fundamental individual e coletivo dos brasileiros.

$\mathrm{O}$ inciso XXXIII do artigo $5^{\circ}$ diz que "Todos têm direito a receber dos órgãos públicos informações de seu interesse particular, ou de interesse coletivo ou geral, que serão prestadas no prazo da lei, sob pena de responsabilidade [...]".

Já o inciso II, do $\S 3^{\circ}$ do artigo 37 prevê que a "A lei disciplinará as formas de participação do usuário na administração pública direta e indireta, regulando especialmente: o acesso dos usuários a registros administrativos e a informações sobre atos de governo [...]".

O artigo 216, §2 , dispõe que “Cabem à administração pública, na forma da lei, a gestão da documentação governamental e as providências para franquear sua consulta ao Patrimônio Cultural Brasileiro".

Por fim, o artigo 220 da Constituiçãotrata da comunicação social utilizando o direito à informação para oferecer as garantias de liberdade de informação, de expressão, de livre manifestação do pensamento e da criação da informação. ${ }^{14}$

Anos se passaram desde a promulgação da Carta Cidadã e, somente em 18 de novembro de 2011, foi sancionada pela então presidente Dilma Rousseff a lei que regulamentou o direito à informação. Com a Lei, a publicidade passou a ser a regra e o sigilo a exceção. Dessa forma, as

13 BRITO, Carlos Ayres. Voto do ministro na ADPF 130, p.42. Disponível em: http://www.stf.jus.br/arquivo/cms/noticiaNoticiaStf/anexo/adpf130.pdf. Acesso em:29 ago. 2017.

14 BRASIL. Constituição (1988). Constituição da República Federativa do Brasil. Disponível em: http://www.planalto.gov.br/ccivil_03/constituicao/constituicao.htm. . Acesso em: 12 ago. 2017. 
pessoas passaram a poder ter acesso a qualquer informação pública produzida ou custodiada pelos órgãos e entidades da Administração Pública. A norma entrou em vigor em 16 de maio de 2012 e criou mecanismos que possibilitaram a qualquer pessoa, física ou jurídica, sem necessidade de apresentar motivo, o recebimento de informações públicas dos órgãos e entidades. $^{15}$

A LAI estabelece duas formas de transparência: a ativa e a passiva. A primeira delas consiste nos conteúdos mínimos a serem divulgados pelo órgão ou ente público, como estrutura organizacional, endereços, horários e locais de atendimento ao público, despesas, repasses e transferências de recursos financeiros, procedimentos licitatórios, contratos celebrados, dados sobre programas, ações, projetos, obras, e respostas às perguntas mais frequentes da sociedade.

Já a transparência passiva consiste no dever de fornecer as informações solicitadas. O serviço de busca e fornecimento de informações deve ser gratuito, salvo no caso de cópia de documentos.

Nesse contexto, as instituições públicas brasileiras passaram a ter grande responsabilidade no que diz respeito ao fornecimento de informações, delimitadas no artigo $4^{\underline{0}}$ da Lei de Acesso como “dados, processados ou não, que podem ser utilizados para produção e transmissão de conhecimento, contidos em qualquer meio, suporte ou formato”. Se a informação estiver disponível, ela deve ser entregue imediatamente ao solicitante. Caso não seja possível conceder o acesso imediato, o órgão ou entidade tem até 20 (vinte) dias para atender ao pedido, prazo que pode ser prorrogado por mais $10(\mathrm{dez})$ dias, se houver justificativa expressa.

A Lei de Acesso contém dispositivos de aplicação imediata a todos os órgãos e entidades, bem como dispositivos que necessitam de regulamentação específica por cada Poder e Ente da Federação, valendo para os três Poderes da União, Estados, Distrito Federal e Municípios, inclusive aos Tribunais de Conta e Ministério Público. Entidades privadas sem fins lucrativos também são obrigadas a dar publicidade a informações referentes ao recebimento e à destinação dos recursos públicos por elas recebidos. ${ }^{16}$

No âmbito do Poder Executivo Federal, a regulamentação específica da Lei de Acesso à

\footnotetext{
${ }^{15}$ BRASIL. Lei $\mathbf{n}^{\circ}$ 12.527, de 18 de novembro de 2011. Regula o acesso a informações previsto no inciso XXXIII do art. $5^{\circ}$, no inciso II do § 30 do art. 37 e no $\S 2^{\circ}$ do art. 216 da Constituição Federal; altera a Lei no 8.112, de 11 de dezembro de 1990; revoga a Lei no 11.111, de 5 de maio de 2005, e dispositivos da Lei no 8.159, de 8 de janeiro de 1991; e dá outras providências. Disponível em: http://www.planalto.gov.br/ccivil 03/ Ato2011-2014/2011/Lei/L12527.htm. Acesso em: 06 dez. 2016.

${ }^{16}$ BRASIL. Lei $\mathbf{n}^{0}$ 12.527, de 18 de novembro de 2011. Regula o acesso a informações previsto no inciso XXXIII do art. $5^{\circ}$, no inciso II do $\S 3$ o do art. 37 e no $\S 2^{\circ}$ do art. 216 da Constituição Federal; altera a Lei no 8.112, de 11 de dezembro de 1990; revoga a Lei no 11.111, de 5 de maio de 2005, e dispositivos da Lei no 8.159, de 8 de janeiro de 1991; e dá outras providências. Disponível em: http://www.planalto.gov.br/ccivil_03/_Ato2011-2014/2011/Lei/L12527.htm. Acesso em: 06dez. 2016.
} 
Informação ocorreu com a publicação do Decreto $\mathrm{n}^{\circ}$ 7.724, em 16 de maio de 2012, que estabeleceu os procedimentos para a garantia do acesso à informação e para a classificação de informações sob restrição de acesso no Governo Federal. ${ }^{17}$

Pode-se dizer que a LAI contribui para promoção da transparência nas instituições públicas e, consequentemente, para uma melhor distinção e julgamento das políticas públicas, uma vez que assegura ao cidadão o conhecimento dos fatos, atos ou omissões no âmbito estatal. Ela representa, no campo jurídico e social, mais um passo para a efetivação das teorias deliberativas e participativas.

Por ser extensa e nova, além de historicamente elaborada sob influência dos principais textos internacionais, a lei brasileira figura bem no Ranking Global de Direito à Informação. O Brasil apareceem $18^{\circ}$ lugar entre 102 países, à frente dos Estados Unidos, Suécia, Noruega, Reino Unido. A avaliação foi feita pelas organizações não governamentais Centre for Law and Democracy (CLD), do Canadá, e Access Info Europe, da Espanha, para medir a qualidade das leis de acesso à informação no mundo.

\section{4 - Evolução do Direito à Informação nos Estados Unidos}

A Constituição dos Estados Unidos foi promulgada em 17 de setembro de 1789, sendo considerada a mais antiga Constituição em vigência do mundo. Desde então, mais de dez mil emendas foram propostas, no entanto, apenas 27 foram aprovadas. Uma de suas principais características, também vista como motivo de sua durabilidade, é o texto sintético. Tal objetividade torna absoluto o grau de discricionariedade da Suprema Corte nos mais variados assuntos, conforme detalhou Arnaldo Godoy (2006):

\footnotetext{
"O direito constitucional norte-americano transcende o texto de 1787 e se realiza nas discussões concretas que apreciam controle de constitucionalidade, poderes implícitos, supremacia de lei federal, relações entre as raças, política do laissez-faire, direito de silêncio, aborto, liberdade religiosa, liberdade de expressão, controle de constitucionalidade de políticas de organizações privadas, jurisdição federal, questões políticas de organização da política, relações entre os poderes, imunidade presidencial, limitação do poder de política e os contornos do próprio ativismo judicial". ${ }^{18}$
}

As normas com vigência em todo o território daquela nação são apenas as federais, uma vez que o federalismo vigora no país. O controle de constitucionalidade substancializou-se na

${ }^{17}$ BRASIL. Decreto $\mathbf{n}^{\mathbf{0}} \mathbf{7 . 7 2 4}$ de 16 de maio de 2012. Regulamenta a Lei $\mathrm{n}^{\mathrm{o}}$ 12.527, de 18 de novembro de 2011, que dispõe sobre o acesso a informações previsto no inciso XXXIII do caput do art. $5^{\circ}$, no inciso II do $\S 3^{\circ}$ do art. 37 e no $\S 2^{\circ}$ do art. 216 da Constituição. Disponível em: http://www.planalto.gov.br/ccivil_03/_ato2011-2014/2012/decreto/d7724.htm. Acesso em: 06 ago. 2017.

${ }_{18}$ GODOY, Arnaldo Sampaio de Moraes. Direito Constitucional Comparado. Porto Alegre: Sergio Antonio Fabris Ed., 2006; p. 51. 
percepção de que nulas são as leis que confrontam o texto constitucional.Traço oriundo da colonização inglesa, a autonomia das unidades da federação dos EUA é uma das principais características deste modelo democrático.

O direito à liberdade de expressão é protegido na Constituição americana de forma negativa, por meio da Primeira Emenda que proíbe o Congresso de aprovar quaisquer leis que restrinjam a liberdade de expressão ou de imprensa. Em 1966, o país criou a sua Lei de Liberdade de Informação (Freedom of Information Act - FOIA) ${ }^{19}$.

Em 1974, o caso Watergate acabou ampliando os efeitos da Lei estabelecendo que órgãos federais deveriam antecipar-se ao interesse dos cidadãos e publicar o máximo possível de informações sobre suas atividades. Além disso, tais entes passaram a ser obrigados a responder prontamente a quem pedir, com base na FOIA, informações não publicadas; podendo o solicitante ser qualquer pessoa ou organização, até mesmo estrangeira ${ }^{20}$.

Em 1984, nova emenda amplia os direitos da CIA de negar acesso a certas informações. Em 1996, o então presidente Bill Clinton assina E-FOIA, adaptando a legislação à revolução tecnológica, principalmente as bases de dados eletrônicas. Já em 2007, os EUA incorporou os princípios dos Dados Abertos, elaborado em encontro na Califórnia por um grupo de 30 pessoas. Chegou-se ao consenso sobre os seguintes oito princípios dos Dados Abertos Governamentais:

“1 - Completos. Todos os dados públicos são disponibilizados. Dados são informações eletronicamente gravadas, incluindo, mas não se limitando a, documentos, bancos de dados, transcrições e gravações audiovisuais. Dados públicos são dados que não estão sujeitos a limitações válidas de privacidade, segurança ou controle de acesso, reguladas por estatutos.

2 - Primários. Os dados são publicados na forma coletada na fonte, com a mais fina granularidade possível, e não de forma agregada ou transformada.

3 - Atuais. Os dados são disponibilizados o quão rapidamente seja necessário para preservar o seu valor.

4 - Acessíveis. Os dados são disponibilizados para o público mais amplo possível e para os propósitos mais variados possíveis.

5 - Processáveis por máquina. Os dados são razoavelmente estruturados para possibilitar o seu processamento automatizado.

6 - Acesso não discriminatório. Os dados estão disponíveis a todos, sem que seja necessária identificação ou registro.

7 - Formatos não proprietários. Os dados estão disponíveis em um formato sobre o qual nenhum ente tenha controle exclusivo.

8 - Livres de licenças. Os dados não estão sujeitos a regulações de direitos autorais, marcas, patentes ou segredo industrial. Restrições razoáveis de privacidade, segurança e controle de acesso podem ser permitidas na forma regulada por estatutos". ${ }^{21}$

Em 2009, a política de abertura de informações como pilar da democracia foi enfatizada

${ }^{19}$ TheFreedom of Information Act, 5 U.S.C. $\$$ 552.Disponívelem: https://www.justice.gov/oip/freedominformation-act-5-usc-552. Acesso em: 02 set. 2017.

${ }^{20}$ TheFreedom of Information Act, 5 U.S.C. $\$$ 552. Alterações à Lei de Liberdade de Informação Eletrônica. Disponível em: https://epic.org/open_gov/efoia.html. Acesso em: 02 set. 2017.

${ }^{21}$ O que são dados abertos? Disponível em: http://dados.gov.br/pagina/dados-abertos. Acesso em: 4 set. 2017. 
pelo presidente Barack Obama que encaminhou ofício aos diretores e chefes de Departamentos e Agências do Executivo, informando sobre a conduta a ser tomada em relação à divulgação de informações. No documento, Obama prega responsabilidade e transparência dos gestores. Dois anos depois, em 2011, a exemplo do Brasil, o país integrou o Open Government Partnership, iniciativa com foco na promoção da transparência, luta contra a corrupção, participação social e de fomento ao desenvolvimento de novas tecnologias.

Como se observou, ao longo dos anos, a legislação federal pró-acesso nos EUA recebeu emendas em várias ocasiões, contribuindo para o que Mendel (2009) classificou como cultura de abertura no governo:

\footnotetext{
“A lei de direito à informação dos Estados Unidos possui uma série de pontos fortes e fracos. Ela incorpora as disposições acerca de taxas, firmes regras sobre o fornecimento eletrônico de informações e um leque de boas medidas de promoção, que foram introduzidas recentemente. Entre os pontos fracos: regras acerca do processamento oportuno de informações que podem ser contornadas, permissão para a restrição de documentos, que teve uma ampliação considerável nos últimos anos, e a ausência de um mecanismo de supervisão administrativa independente, dotado do poder de receber reclamações sobre a não aplicação adequada das regras pelos órgãos públicos". ${ }^{22}$
}

Não há no país um órgão central que atenda a todos os pedidos de informação feitos em todas as agências federais. O cidadão que deseja verificar determinada informação deve dirigir-se à agência de seu interesse e preencher um requerimento por escrito para extrair a informação. A resposta a um pedido de informação, conforme a lei dos EUA, tem que ser dada em dez dias no primeiro pedido e 20 na apelação. As repartições federais têm 30 dias para responder ao tribunal no caso de recurso. Na dúvida sobre isenção, o juiz federal deve ter acesso ao documento para decidir se o libera. Cada repartição tem de informar o Congresso sobre todos os documentos que se negou a liberar no ano e explicar os motivos em cada caso.

\section{5 - Análise Comparativa}

Nos capítulos anteriores, foi demonstrada, em linhas gerais, a evolução do direito à informação no Brasil e nos Estados Unidos da América. Uma leitura atenta demonstra que na conquista pela transparência nas instituições públicas a ação dos instrumentos internacionais de proteção de direitos humanos teve fundamental importância - seja pressionando ou servindo de referência para os textos nacionais - para uma constante evolução no direito de saber. Como exposto, os países estão reconhecendo que os indivíduos têm direito à informação mantida por órgãos públicos, porém, cada um ao seu modo vem trabalhando para a efetivação deste direito na prática.

${ }^{22}$ MENDEL, Toby. Liberdade de Informação: um estudo de direito comparado. 2. ed.Brasília: Unesco, 2009. p.138 
Por sua tradição jurídica, o Brasil precisou regulamentar um dispositivo constitucional para que este direito produzisse impactos na dinâmica real do poder. Mesmo com leis anteriores, somente em 2012 o país tornou efetiva uma política de abertura de dados públicos. Antes disso, dezenas de relatórios internacionais apontavam a violação do direito de acesso à informação no Brasil, protegida por essa falta de regulamentação.

Já a Lei de Liberdade de Informação americana faz parte de um arsenal jurídico em vigor há décadas que garante a aplicação na prática de dois princípios básicos: "open government" (governo aberto) e "right to know" (o direito a saber).Ocorre que a ausência de instruções mais pragmáticas naquele ordenamento acaba por restringir o acesso às informações do Poder Executivo, por meio da interpretação.

Outro fator que diferencia EUA e Brasil diz respeito à forma de federalismo. Cada estado americano tem Executivo e Legislativo bicameral, e cada um dispõe como convém acerca da organização judiciária. Consequentemente, cada um dos 50 Estados-membro dispõede leis próprias de direito à informação, já que a Freedom of Information Act (FOIA) é uma lei federal e só se refere a órgãos federais. Por esse modelo, muitas matérias que, no Brasil, são da competência da União, nos EUA são da competência dos Estados-membros. Lenza (2011) faz uma síntese da comparação do federalismo norte-americano ao brasileiro:

\begin{abstract}
"Os pontos em comum do federalismo desses dois países são: descentralização política, repartição de competências, constituição rígida como base jurídica, inexistência de direito de secessão, soberania do Estado federal, intervenção, auto-organização dos Estados-membros (constituições estaduais), órgãos representativos dos Estadosmembros, guardião da Constituição e repartição de receitas". ${ }^{23}$
\end{abstract}

Inserindo os países ora analisados nos grandes sistemas do direito contemporâneo é possível identificar duas famílias jurídicas distintas, tomando como base elementos da macrocomparação. Muitos autores fazem tal classificação para facilitar as exposições descritivas e fornecer informações particulares de determinados sistemas. A título exemplificativo, Duarte (2006) descreve os seguintes agrupamentos:

"-O primitivo David chegava aos sistemas ocidental, soviético, muçulmano, hindu e chinês;

-Arminjon, Nolde e Wolffapontaram: as famílias francesa, alemã, escandinava, inglesa, islâmica e hindu;

- Oliveira Ascensão distinguiu entre Direitos primitivos e civilizados e, de entre estes, o muçulmano, o ocidental (com os subgrupos romanísticos e anglo-americano) e o socialista;

- último David colocou numa primeira linha, em função da sua proximidade cultural, as famílias romano-germânica, dos Direitos socialistas e da common law e numa segunda linha os direitos muçulmano, da Índia, do Extremo-Oriente e da África e Madagascar;

- Zweigert e Kötz' distinguiram os círculos romanístico (ou "românico"), germânica, anglo-americano, nórdico, socialista, do Extremo-Oriente, islâmico e hindu;

${ }^{23}$ LENZA, Pedro. Direito Constitucional Esquematizado. 15. Ed. São Paulo: Saraiva, 2011. p. 382. 
-circunscrevendo-se aos Direitos de cultura europeia, Wieacker distinguiu os círculos anglo-saxônico, francês ou românico e centro-europeu;

- Fikentscher, na sua abordagem comparativa dos métodos do Direito apontou também os círculos românico, anglo-americano e da Europa Central.

-Galvão Telles, em obra acabada de escrever em Novembro de 1999, identifica cinco sistemas: romanista, anglo-americano, muçulmano, hindu e chinês"24.

Pela classificação de Rui Pinto Duarte, dentro do chamado mundo ocidental, haverá apenas que considerar duas famílias: a romano-germânica (ou da civil law, na terminologia anglo-americana) e a da common law (muitas vezes chamada anglosaxônica, mas a que preferimos chamar anglo-americana) ${ }^{25}$.

A Common Law é uma família de direito que se baseia no costume e nas decisões da Corte de Justiça, ou seja, no precedente judiciário. A fonte do common law é essencialmente a jurisprudência; suas regras são, fundamentalmente, as que se encontram nas decisões tomadas pelos tribunais e os chamados 'leading cases'. Esse é o caso da maioria dos Estados-membros dos EUA.

Já o Brasil está localizado na família romano-germânico que teve origem no Direito Romano. A compilação e codificação consolidam um modelo que sempre procura deixar a lei escrita, sistematizada, afastando a jurisprudência casuística em favor da doutrina. Ao contrário da Common Law, o costume e a jurisprudência foram renegados em favor da lei escrita.

Passada essa classificação, o presentecapítulo busca identificar os temasconsensuais, bem como pontos de discordância das leis de acesso à informação. Para fins metodológicos, a comparação é feita com base nos princípios que nortearam as legislações pró-acesso em todo o mundo, conforme o relatório da UNESCO "Liberdade de Informação: um estudo de direito comparado", assinado por Toby Mendel. O documento aponta nove princípios que caracterizam um regime de direito à informação: máxima divulgação, obrigação de publicar, promoção de um governo aberto, limitação de abrangência de exceções, procedimentos que facilitem o acesso, custos, reuniões abertas, a divulgação tem precedência e proteção aos denunciantes ${ }^{26}$.

\section{1 - Princípio da Máxima Divulgação}

Este princípio implica que a abrangência do direito à informação deve ser ampla no tocante às informações e órgãos envolvidos, bem como quanto aos indivíduos que poderão reivindicar

${ }^{24}$ DUARTE, Rui Pinto. Uma introdução ao Direito Comparado. Lisboa: Edições Almedina, 2006. Separata da Revista "O Direito IV", 138.ed.

${ }^{25}$ DUARTE, Rui Pinto. Uma introdução ao Direito Comparado. Lisboa: Edições Almedina, 2006. Separata da Revista "O Direito IV", 138.ed.

${ }^{26}$ MENDEL, Toby. Liberdade de Informação: um estudo de direito comparado. 2. ed.Brasília: UNESCO, 2009.p.149 
este direito; estabelecendo a presunção de que toda informação é acessível sujeita somente a um sistema estrito de exceções.

Pelo padrão da ONU, os órgãos públicos têm a obrigação de revelar informações, entendendo-se por "informações" todos os registros mantidos por órgão público, independentemente de sua forma de armazenamento ${ }^{27}$.

O incremento da lei americana promovido pela adesão a Tratados e Convenções internacionais leva ao entendimento de que a divulgação, e não o sigilo, constitui o objetivo predominante da lei. Além disso, a seção 2 da FOIA estabelece reconhecimento à noção do direito à informação conforme é reconhecido pelo direito internacional: o Congresso deve examinar a lei, periodicamente, a fim de determinar se há necessidade de novas modificações para efetivar não a "necessidade de informação", mas o "direito à informação fundamental". ${ }^{28}$

No caso do Brasil, o caput do artigo $1^{\circ}$ da lei já trata da abrangência da lei, ao dispor sobre procedimentos a serem observados pela União, Estados, Distrito Federal e Municípios, com o fim de garantir o acesso a informações. O núcleo conceitual gira em torno do dever do Estado de garantir o direito de acesso à informação, que será franqueada, mediante procedimentos objetivos e ágeis, de forma transparente, clara e em linguagem de fácil compreensão.

Estão subordinados órgãos públicos integrantes da administração direta dos Poderes Executivo, Legislativo, incluindo as Cortes de Contas, e Judiciário e do Ministério Público. ${ }^{29}$

No tocante à amplitude da lei nos dois países, verifica-se um esforço em alinhar os sistemas às medidas cobradas pelos organismos internacionais de proteção à democracia. Ou seja, o direito à informação é reconhecido como direito fundamental que deve ser aprimorado, visando o princípio da máxima divulgação.

\section{2 - Princípio da obrigação de publicar}

O acesso efetivo para muitas pessoas depende de que esses órgãos publiquem e divulguem, efetivamente, voluntariamente, de forma proativa, sem necessidade de requisição, categoriaschave de informação, mesmo na ausência de um pedido. Isso é refletido em uma série de declarações internacionais com vistas a promover a transparência da administração pública,

${ }^{27}$ MENDEL, Toby. Liberdade de Informação: um estudo de direito comparado. 2. ed. Brasília: Unesco, 2009. p.34

${ }^{28}$ TheFreedom of Information Act, 5 U.S.C. § 552.Lei $\mathbf{n}^{\mathbf{0}}$ 12.527, de 18 de novembro de 2011 Disponível em: https://www.justice.gov/oip/freedom-information-act-5-usc-552. Acesso em: 02set.2017.

${ }^{29}$ BRASIL. Lei $\mathbf{n}^{\mathbf{0}} \mathbf{1 2 . 5 2 7}$, de 18 de novembro de 2011. Disponível em: http://www.planalto.gov.br/ccivil_03/_Ato2011-2014/2011/Lei/L12527.htm. Acesso em: 06 dez. 2016. 
eficiência administrativa e participação bem informada da população ${ }^{30}$.

No Brasil, o Capítulo II da Lei 12.527/2011 se dedica exclusivamente ao acesso e divulgação de informações. $\mathrm{O}$ art. $8^{\circ}$ é taxativo ao afirmar que é dever dos órgãos e entidades públicas promover, independentemente de requerimentos, a divulgação em local de fácil acesso, no âmbito de suas competências, de informações de interesse coletivo ou geral por eles produzidas ou custodiadas. No $\S 2^{\circ}$, a internet é mencionada como meio de divulgação das informação nos sites dos órgãos e entidades públicas. ${ }^{31}$

A lei dos EUA também prescreve que cada agência deve disponibilizar um leque de informações para consulta e cópia pelo público. Também existe previsão da divulgação na internet. A diferença está na inclusão dos procedimentos a serem adotados por Estados e municípios, presente na legislação brasileira e que não ocorre no sistema de acesso à informção americano.

\section{3 - Princípio da promoção de um governo aberto}

Um leque de medidas promocionais pode ser necessário para tratar da cultura do sigilo e assegurar que a população esteja ciente do direito à informação e de suas implicações. Ampla gama de medidas, nesse sentido, pode ser tomada para educar a população. Os meios de comunicação podem desempenhar papel primordial nessa parte; a mídia eletrônica pode assumir posição de grande importância nos países em que a distribuição de jornais seja fraca ou os índices de analfabetismo sejam altos. Outra ferramenta útil, prevista em várias leis de direito à informação, é a publicação de um guia simples e acessível sobre como fazer uma solicitação de informações ${ }^{32}$.

$\mathrm{O}$ art. 41 da LAI atribui ao Poder Executivo Federal a obrigação de designar órgão da administração pública federal responsável pela promoção de campanha de abrangência nacional de fomento à cultura da transparência na administração pública e conscientização do direito fundamental de acesso à informação. Além disso, pelo treinamento de agentes públicos, pelo monitoramento da aplicação da lei e pelo encaminhamento ao Congresso Nacional de relatório anual com informações atinentes à implementação desta Lei. ${ }^{33}$ Ou seja, a legislação brasileira

${ }^{30}$ MENDEL, Toby. Liberdade de Informação: um estudo de direito comparado. 2. ed.Brasília: Unesco, 2009.p.34.

${ }^{31}$ BRASIL. Lei $\mathbf{n}^{\mathbf{0}} \mathbf{1 2 . 5 2 7}$, de 18 de novembro de 2011. Disponível em: http://www.planalto.gov.br/ccivil 03/ Ato2011-2014/2011/Lei/L12527.htm. Acesso em: 06 dez. 2016.

${ }_{32}$ MENDEL, Toby. Liberdade de Informação: um estudo de direito comparado. 2. ed.Brasília: Unesco, 2009.p.34.

${ }^{33}$ BRASIL. Lei $\mathbf{n}^{\mathbf{0}} \mathbf{1 2 . 5 2 7}$, de 18 de novembro de 2011 . Disponível em: http://www.planalto.gov.br/ccivil_03/_Ato2011-2014/2011/Lei/L12527.htm. Acesso em: 06 dez. 2016. 
caminha no mesmo sentido do princípio da promoção de um governo aberto; sendo a prática fortalecida mais recentemente pela criação do Ministério da Transparência, cuja função é realizar atividades relacionadas à defesa do patrimônio público e ao incremento da transparência da gestão, por meio de ações de controle interno, auditoria pública, correição, prevenção e combate à corrupção e ouvidoria.

O modelo é parecido nos EUA no que diz respeito ao monitoramento, recomendações quanto a mudanças necessárias e fomento à conscientização pública sobre as finalidades das exceções. Os órgãos públicos devem apresentar à Procuradoria-Geral relatórios anuais acerca de suas atividades relativas à lei, devendo os relatórios ser disponibilizados ao público, inclusive por meios eletrônicos.

Tanto no Brasil quanto nos Estados Unidos, ainda não se sabe qual será o grau de eficácia, na prática, da implementação dos planos. A divulgação da política pública de transparência, nos dois casos, é fomentada ainda pela ação de ONGs.

\section{4 - Princípio da limitação da abrangência de exceções}

Em alguns casos, leis de direito à informação que de outra forma teriam grande efetividade são prejudicadas em grande parte por um regime de exceções excessivamente amplo e aberto. Por outro lado, é obviamente importante que todos os interesses legítimos de sigilo recebam a devida consideração, do contrário os órgãos públicos seriam licitamente obrigados a divulgar informações, mesmo que isso pudesse causar danos desproporcionais ${ }^{34}$.

O caso brasileiro não é considerado amplo e aberto. As informações sob a guarda do Estado são públicas, devendo o acesso a elas ser restringido apenas em casos específicos e por período de tempo determinado.Segundo a LAI, são exceções à regra de acesso os dados pessoais, as informações classificadas por autoridades como sigilosas e as informações sigilosas com base em outras leis. $^{35}$

O disposto no Art. 14 prevê que é direito do requerente obter o inteiro teor de decisão de negativa de acesso, por certidão ou cópia. Já o Art. 16 prevê que negado o acesso a informação pelos órgãos ou entidades do Poder Executivo Federal, o requerente poderá recorrer à Controladoria-Geral da União, que deliberará no prazo de 5 (cinco) dias. A atuação do Ministério

\footnotetext{
${ }^{34}$ MENDEL, Toby. Liberdade de Informação: um estudo de direito comparado. 2. ed.Brasília: Unesco, 2009.p.36.

${ }^{35}$ Segundo o site do Ministério da Transparência, informações classificadas como sigilosas são aquelas que a divulgação possa colocar em risco a segurança da sociedade (vida, segurança, saúde da população) ou do Estado (soberania nacional, relações internacionais, atividades de inteligência). Por isso, apesar de serem públicas, o acesso a elas deve ser restringido por meio da classificação da autoridade competente.
} 
da Transparência, designada para fiscalizar o cumprimento da LAI, costuma assegurar um pouco mais de transparência. Ainda assim, é possível encontrar muitos casos em que os pedidos de informação não são atendidos por órgãos federais. ${ }^{36}$

A lei americana também é contundente no sentido de impor um regime restrito de exceções na divulgação de informações. É importante observar, porém, que enquanto algumas agências do nível federal até o nível local se adaptam às exigências de transparência, muitas elaboraram estratégias alternativas - impondo taxas exorbitantes, barreiras burocráticas e exceções discricionárias para negar documentos que são essenciais para elucidar histórias importantes. É o que revela o jornalista Jason Leopold em artigo publicado em abril de 2017 denominado "Obstáculos à Liberdade de Informação".

Especializado em reportagens sobre segurança nacional, Leopold denunciou que agências americanas exploram todas as lacunas para evitar cumprir os requerimentos de revelação. Segundo ele, as agências governamentais restringem o fluxo de informações públicas:

\footnotetext{
"As leis de registros públicos dos EUA são o padrão global, e muitos outros países olham para a América como um exemplo. No entanto, à medida que me aprofundei no assunto, observei uma tendência de compensação: agências governamentais que parecem estar dispostas a me manter - e ao público - no escuro, muitas vezes contrariando os requisitos de transparência, o equivalente à censura burocrática, apesar das diretrizes superiores contrárias e das leis estaduais e federais de transparência". ${ }^{37}$
}

De acordo com o relatório de Mendel (2009), a lei dos EUA concentra-se no poder Executivo do governo, sem englobar o poder Legislativo (o Congresso), os Tribunais, tampouco alguns setores do Gabinete Executivo do Presidente, inclusive, por exemplo, o Conselho de Segurança Nacional e o Conselho da Casa Branca. A abrangência também não alcança órgãos privados com custeio público considerável ou com funções públicas ${ }^{38}$. Dessa forma, pode-se considerar que possui abrangência limitada em comparação com o Brasil.

\section{5 - Procedimentos que facilitem o acesso}

Os pedidos de informação devem ser processados com rapidez e justiça, com a possibilidade de um exame independente em caso de recusa. Os Padrões da ONU defendem a exigência de que os órgãos públicos "instaurem sistemas abertos e acessíveis a fím de assegurar o direito da população de receber informações", fazendo referência específica, a este respeito, à

${ }^{36}$ BRASIL. Lei $\mathbf{n}^{\mathbf{0}}$ 12.527, de 18 de novembro de 2011. Disponível em: http://www.planalto.gov.br/ccivil 03/ Ato2011-2014/2011/Lei/L12527.htm. Acesso em: 06 dez. 2016.

${ }^{37}$ Obstáculos à Liberdade de Informação. Jason Leopold. Disponível em: https://cpj.org/pt/2017/04/obstaculos-a-liberdade-de-informacao.php. Acesso em: 03 set. 2017.

${ }^{38}$ MENDEL, Toby. Liberdade de Informação: um estudo de direito comparado. 2. ed.Brasília: Unesco, 2009.p.152. 
necessidade de "limites de tempo rigorosos para o processamento de pedidos de informação", e o fornecimento de notificação de eventuais recusas para proporcionar acesso que inclua "motivos concretos, por escrito, para a(s) recusa(s)". 39

O assunto é tratado na Lei de Acesso à Informação do Brasil no Capítulo III, na abordagem da transparência passiva. Dos artigos 10 a 14, é assegurado que o pedido de informação não necessita de justificação, devendo apenas conter sua especificação e a identidade do requerente. A resposta deve ser oferecida no prazo máximo de vinte dias, prorrogáveis por mais dez mediante justificativa expressa e ciência ao solicitante. O serviço de busca e fornecimento de informações deve ser gratuito, salvo no caso de cópia de documentos ${ }^{40}$.

A lei dos Estados Unidos, ao receber emendas, incorporou regras detalhadas acerca de prazos. A exemplo do Brasil, as solicitações deverão receber resposta dentro de 20 dias úteis. Em “circunstâncias incomuns", o prazopoderá ser prorrogado por mais 10 dias, mediante aviso prévio. $^{41}$

\section{6 - Custos}

As pessoas não devem ser impedidas de fazer pedidos de informação em razão dos altos custos envolvidos ${ }^{42}$.

No Art. 12 da LAI, fica expressa a gratuidade do serviço de busca e fornecimento da informação, salvo nas hipóteses de reprodução de documentos pelo órgão ou entidade pública consultada, situação em que poderá ser cobrado exclusivamente o valor necessário ao ressarcimento do custo dos serviços e dos materiais utilizados. No parágrafo único deste artigo, a exceção ocorre para aquele cuja situação econômica não lhe permita fazê-lo sem prejuízo do sustento próprio ou da família, declarada nos termos da Lei no 7.115, de 29 de agosto de $1983 .{ }^{43}$

Diferente do Brasil, a lei dos Estados Unidos prescreve regras pormenorizadas acerca das taxas que poderão ser cobradas para a resposta a solicitações de informação. Conforme descrito, cada órgão deve promulgar regulamentos, de acordo com aviso prévio e recepção de comentários

${ }^{39}$ MENDEL, Toby. Liberdade de Informação: um estudo de direito comparado. 2. ed.Brasília: Unesco, 2009.p.38.

${ }^{40}$ BRASIL. Lei $\mathbf{n}^{\mathbf{0}} \mathbf{1 2 . 5 2 7}$, de 18 de novembro de 2011. Disponível em: http://www.planalto.gov.br/ccivil_03/_Ato2011-2014/2011/Lei/L12527.htm. Acesso em: 06 dez. 2016.

${ }^{41}$ TheFreedom of Information Act, 5 U.S.C. $\$ 552$.DisponívelLei $\mathbf{n}^{\circ} \mathbf{1 2 . 5 2 7}$, de 18 de novembro de 2011. Disponível em: https://www.justice.gov/oip/freedom-information-act-5-usc-552. Acesso em: 02set. 2017.

${ }^{42}$ MENDEL, Toby. Liberdade de Informação: um estudo de direito comparado. 2. ed. Brasília: Unesco, 2009.p.40

${ }^{43}$ BRASIL. Lei $\mathbf{n}^{\mathbf{0}}$ 12.527, de 18 de novembro de 2011. Disponível em: http://www.planalto.gov.br/ccivil_03/_Ato2011-2014/2011/Lei/L12527.htm. Acesso em: 06 dez. 2016. 
públicos, especificando o cronograma das taxas aplicáveis ao processamento de pedidos sob esta seção e estabelecendo procedimentos e diretrizes para determinar quando essas taxas deve ser renunciado ou reduzido. Esse cronograma deve estar em conformidade com as diretrizes que serão promulgadas, de acordo com o aviso e recebimento de comentários públicos, pelo Diretor do Escritório de Gestão e Orçamento e que deverá prever um cronograma uniforme de tarifas para todas as agências. ${ }^{44}$

\section{7 - Reuniões Abertas}

As reuniões de órgãos públicos devem ser abertas ao público.Os Padrões da ONU corroboram isso: "A lei [sobre direito a informação] deveria estipular a presunção de que todas as reuniões dos órgãos do governo fossem abertas ao público". ${ }^{45}$

Em termos práticos, são raros, porém não desconhecidos, os casos de leis de direito à informação que determinam a abertura das reuniões dos órgãos públicos. O princípio ainda não rege a atuação dos países analisados.

\section{8 - Divulgação tem precedência}

As leis que não estejam de acordo com o princípio da máxima divulgação devem ser revisadas ou revogadas. O direito internacional não dita a forma de implementação das regras dos Estados, inclusive na área de direitos humanos fundamentais, o que também se aplica ao direito a informação. Em decorrência disso, cabe aos Estados determinar o tratamento da questão das exceções ao direito de acesso ${ }^{46}$.

No caso dos países analisados, a regulamentação do direito de acesso e o debate sobre a revisão de dispositivos fica a cargo das entidades da sociedade civil, imprensa e Poder Legislativo. O direito internacional atua como referência para as mudanças legislativas.

\section{9 - Proteção para denunciantes}

Os indivíduos que trazem à público informações sobre atos ilícitos - os denunciantes precisam ser protegidos. Tal medida é importante para mudar a cultura de sigilo no âmbito do

${ }^{44}$ TheFreedom of Information Act, 5 U.S.C. $\S 552$.DisponívelLei $\mathbf{n}^{\mathbf{0}} \mathbf{1 2 . 5 2 7}$, de 18 de novembro de 2011. Disponível em: https://www.justice.gov/oip/freedom-information-act-5-usc-552. Acesso em: 02set. 2017.

${ }^{45}$ MENDEL, Toby. Liberdade de Informação: um estudo de direito comparado. 2. ed.Brasília: Unesco, 2009.p.40.

${ }^{46}$ MENDEL, Toby. Liberdade de Informação: um estudo de direito comparado. 2. ed.Brasília: Unesco, 2009.p.41 
governo e para fomentar um clima de abertura. Com frequência, não fica claro se a divulgação de informações sobre atos ilícitos é afiançada pela lei, mesmo que a lei inclua a prevalência do interesse público, e não se pode esperar que os indivíduos que estejam procurando divulgar informações de interesse público realizem uma complexa conciliação dos diferentes interesses que possam estar em jogo. ${ }^{47}$

$\mathrm{Na}$ lei brasileira, o termo proteção aparece em seis ocasiões. Em cinco citações, a palavra está ligada ao termo informação (proteção da informação). $\mathrm{Na}$ última menção, na seção $\mathrm{V}$, Das informações pessoais, consta como "proteção do interesse público". O termo denunciante não aparece na Lei de Acesso à Informação brasileira. Há dezenas de registros de eventos e projetos de lei tratando de formas de incorporar ao sistema jurídico nacional um programa de incentivo e proteção a denunciantes. Porém, ainda não ouve avanço legislativo nesse sentido.

Nos Estados Unidos, de acordo com Mendel, há Ordem Executiva contra a retaliação dos funcionários que fazem questionamentos acerca de informação imprópria. Uma série de leis, inclusive a Lei Sarbanes-Oxley, de 2002, proporciona certa proteção aos denunciantes, mas ainda não há legislação abrangente que resguarde os denunciantes. ${ }^{48}$

Dessa forma, infere-se que a proteção dos denunciantes é assunto que ainda demanda esforço nos dois países.

\section{6 - Considerações finais}

Os estudos sobre as políticas públicas e seus ciclos mostram que toda política pública representa uma tentativa de intervenção na realidade social. A intervenção pode ser de controle ou de mudança, influenciada pela percepção pública de que uma situação indesejada requer medidas transformadoras.

As medidas adotadas pelo Brasil para o enfrentamento da demanda por mais transparência caminham no mesmo sentido das nações consideradas desenvolvidas democraticamente, tanto quanto dos principais instrumentos internacionais de proteção do direito à informação. $\mathrm{O}$ momento histórico de regulamentação deste direito que inclui o cidadão na vida democrática ocorre, coincidentemente ou não, num cenário de maior envolvimento da sociedade civil na luta contra a corrupção; um ano antes das manifestações de julho de 2013 em todo país;

${ }^{47}$ MENDEL, Toby. Liberdade de Informação: um estudo de direito comparado. 2. ed.Brasília: Unesco, 2009.p.42

${ }^{48}$ MENDEL, Toby. Liberdade de Informação: um estudo de direito comparado. 2. ed.Brasília: Unesco, 2009.p.145 
em período próximo aos primeiros desdobramentos da Operação Lava Jato; e num cenário de fortalecimento da participação popular nas redes sociais.

No tocante aos nove princípios que caracterizam um regime de direito à informação no mundo, segundo o relatório da UNESCO, sem dúvida, a pesquisa de direito comparado entre Brasil e Estados Unidos mostra que ainda falta muito para termos um poder público realmente transparente e que preste as devidas contas à sociedade.

Tecnicamente, o ordenamento brasileiro se diferencia do americano em muitos pontos. $\mathrm{O}$ principal deles é que o Brasil possui uma lei mais recente e mais detalhada, o que aproxima o país das modernas diretrizes internacionais. Enquanto que a ausência de instruções mais pragmáticas faz com que os EUA seja considerado ultrapassado por muitos, mesmo que, ao longo dos anos, a legislação tenha recebido emendas.

Por outro lado, foi possível identificar a demora na regulamentação deste direito no Brasil, durando mais de duas décadas. Consequentemente, é possível identificar que Estados, municípios e órgãos da União ainda trabalham para assimilar os preceitos da lei, o que também atrasa o desenvolvimento do controle social. O atraso também ocorreu nos EUA por conta do modelo de federalismo que permite que cada um dos 50 Estados-membro faça sua própria regulamentação.

Mesmo dispondo de uma legislação pró-acesso mais antiga, o país ainda registra em suas agências casos de ausência de recursos adequados para processar pedidos de informação, prorrogações injustificadas e/ou usadas com propósito político e filas de espera que duram décadas. Com a atribuição dos Estados, fica prejudicada a supervisão da não aplicação da lei, uma vez que também foi observada a ausência de um mecanismo de controle e de uma instância de apelação independente. No Brasil, como foi dito, o trabalho fica a cargo da ControladoriaGeral da União.

A presente pesquisa realçou o que já foi dito em inúmeras ocasiões: a adoção de uma lei de direito à informação progressista é apenas o primeiro passo para a concretização do direito à informação na prática. É de se concluir que o reconhecimento deste direito no mundo se fortalece na medida em que as democracias pedem a participação do cidadão na gestão das coisas do Estado - pressionando governos, mandatos e gestores por mais transparência e integridade no uso dos recursos públicos.

Cada vez mais, o cidadão cansado do mundo das desigualdades sociais, pede mudanças, quer participar, saber, tanto quanto exige de seus governante equipamentos públicos de qualidade. Historicamente transformados, querem estar a serviço da transformação. 


\section{7 - Referências Bibliográficas}

ANCEL, Marc. Utilidade e métodos do Direito Comparado: elementos de introdução geral ao estudo comparativo dos direitos. Porto Alegre, Sérgio Antônio Fabris, 1980.

BRASIL. Constituição (1988). Constituição da República Federativa do Brasil. Disponível em: http://www.planalto.gov.br/ccivil_03/constituicao/constituicao.htm.Acesso em: 12 ago. 2017.

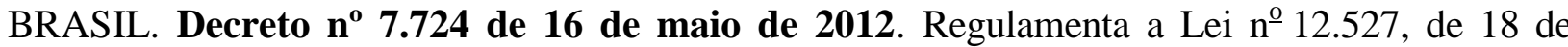
novembro de 2011, que dispõe sobre o acesso a informações previsto no inciso XXXIII do caput do art. $5^{\circ}$, no inciso II do $\S 3^{\circ}$ do art. 37 e no $\S 2^{\circ}$ do art. 216 da Constituição. Disponível em: http://www.planalto.gov.br/ccivil_03/_ato2011-2014/2012/decreto/d7724.htm. Acesso em: 06 ago. 2017.

BRASIL. Lei Complementar $\mathbf{n}^{\mathbf{0}}$ 101, de 04 de maio de 2000. Estabelece normas de finanças públicas voltadas para a responsabilidade na gestão fiscal e dá outras providências. Disponível em: http://www.planalto.gov.br/ccivil_03/leis/LCP/Lcp101.htm.Acesso em: 06 ago. 2017.

BRASIL. Lei Complementar $n^{0}$ 131, de 27 de maio de 2009. Acrescenta dispositivos à Lei Complementar $\mathrm{n}^{\mathrm{0}}$ 101, de 4 de maio de 2000, que estabelece normas de finanças públicas voltadas para a responsabilidade na gestão fiscal e dá outras providências, a fim de determinar a disponibilização, em tempo real, de informações pormenorizadas sobre a execução orçamentária e financeira da União, dos Estados, do Distrito Federal e dos Municípios. Disponível em: http://www.planalto.gov.br/ccivil_03/leis/lcp/lcp131.htm. Acesso em: 06 ago. 2017.

BRASIL. Lei $\mathbf{n}^{\circ} \mathbf{1 2 . 5 2 7}$, de 18 de novembro de 2011. Regula o acesso a informações previsto no inciso XXXIII do art. $5^{\circ}$, no inciso II do $\S 30$ do art. 37 e no $\S 2^{\circ}$ do art. 216 da Constituição Federal; altera a Lei no 8.112, de 11 de dezembro de 1990; revoga a Lei no 11.111, de 5 de maio de 2005, e dispositivos da Lei no 8.159, de 8 de janeiro de 1991; e dá outras providências. Disponível em: http://www.planalto.gov.br/ccivil_03/_Ato2011-2014/2011/Lei/L12527.htm. Acesso em: 05 ago. 2017.

BRITO, Carlos Ayres. Voto do ministro na ADPF 130, p.42. Disponível em: http://www.stf.jus.br/arquivo/cms/noticiaNoticiaStf/anexo/adpf130.pdf. Acesso em: 29ago. 2017.

Declaração dos Direitos do Homem e do Cidadão. 1789. Disponível em: http://pfdc.pgr.mpf.mp.br/atuacao-e-conteudos-de-apoio/legislacao/direitoshumanos/declar_dir_homem_cidadao.pdf. Acesso em: 02 ago. 2017.

Declaração Parceria Governo Aberto. Disponível em: http://www.governoaberto.cgu.gov.br/central-de-conteudo/documentos/arquivos/declaracaogoverno-aberto.pdf. Acesso em: 04 set. 2017.

DUARTE, Rui Pinto. Uma introdução ao Direito Comparado. Lisboa: Edições Almedina, 2006. Separata da Revista "O Direito IV", 138.ed.

GODOY, Arnaldo Sampaio de Moraes. Direito Constitucional Comparado. Porto Alegre: Sergio Antonio Fabris Ed., 2006.

LENZA, Pedro. Direito Constitucional Esquematizado. 15. ed. São Paulo: Saraiva, 2011. 
LEOPOLD, Jason. Obstáculos à Liberdade de Informação.Disponível em: https://cpj.org/pt/2017/04/obstaculos-a-liberdade-de-informacao.php. Acesso em: 03set. 2017.

MENDEL, Toby. Liberdade de Informação: um estudo de direito comparado. 2. ed. Brasília: Unesco, 2009.

O que são dados abertos? Disponível em: http://dados.gov.br/pagina/dados-abertos. Acesso em: 04 set. 2017.

ONU. Convenção das Nações Unidas contra a Corrupção. 2005.Disponível em: https://www.unodc.org/documents/lpobrazil//Topics_corruption/Publicacoes/2007_UNCAC_Por t.pdf. Acesso em: 22 ago. 2017.

ONU. Declaração Interamericana de Princípios de Liberdade de Expressão. 2000. Disponível

https://www.cidh.oas.org/basicos/portugues/s.Convencao.Libertade.de.Expressao.htm. Acesso em: 02 ago. 2017.

ONU. Declaração Universal dos Direitos Humanos. 1948. Disponível em: http://www.ohchr.org/EN/UDHR/Documents/UDHR_Translations/por.pdf. Acesso em: 02 ago. 2017.

TheFreedom of Information Act, 5 U.S.C. \$ 552. Alterações à Lei de Liberdade de Informação Eletrônica. Disponível em: https://epic.org/open_gov/efoia.html. Acesso em: 02 set. 2017.

TheFreedom of Information Act, 5 U.S.C. $\$$ 552.em: https://www.justice.gov/oip/freedominformation-act-5-usc-552. Acesso em: 02 set. 2017. 